\title{
Normatização, grupo e ódio: dinâmica em comentários nas redes sociais
}

\author{
Angelo Carnieletto Müller \\ Doutorando do Programa de \\ Pós-Graduação em Comunicação da \\ Pontifícia Universidade Católica do \\ Rio Grande do Sul (PPGCOM-PUCRS) e \\ mestre em Comunicação. Membro do \\ Grupo de Pesquisa em Comunicação, \\ Emoção e Conflito. \\ E-mail: angelo.muller@acad.pucrs.br
}

\section{Manuel Petrik}

Doutorando do Programa de Pós-Graduação em Comunicação da Pontifícia Universidade Católica do Rio Grande do Sul (PPGCOM-PUCRS) e mestre em Comunicação. Membro do Grupo de Pesquisa em Comunicação, Emoção e Conflito.

E-mail: manuel.pereira@acad.pucrs.br
Resumo: O artigo aborda a normatização de comportamentos nas redes sociais, a fim de compreender de que forma ela contribui para o surgimento de manifestações de ódio. Parte-se da ideia do intento normativo como resultado dialético da vontade individual e da determinação social, detendose sobre as generalizações e como elas tendem à normatização, e aplicando esses preceitos sobre comentários em uma publicação do jornal El País, em seu perfil no Facebook, gerados a partir de uma notícia sobre o voto do deputado Tiririca durante o processo que decidiria sobre a aceitação do impeachment da presidente Dilma Rousseff.

Palavras-chave: Comunicação política; Normatização; Ódio; Conflito.

\section{Normativity, groups, and hatred: dynamics of comments on social networks}

Abstract: The study discusses the regulation of behavior in social networks, in order to understand how it contributes to the emergence of expressions of hate. It starts with the idea of the normative intent as a dialectical result of individual will and social order; it focuses on generalizations and how they tend to become a set of rules. These precepts are applied in comments of a publication in Facebook's profile of El País newspaper, generated from a report about the vote of Tiririca deputy during the session that would decide the acceptance of the impeachment of Dilma Rousseff.

Keywords: Political communication; Normative acts; Hate; Conflict. 


\section{Projetos e normatização}

Um enunciado é um projeto. A habilidade natural da fala do ser humano depende de um código estruturado - a linguagem - para que se realize plenamente. $O$ ato de fala é composto, portanto, de início, por uma relação dialética entre uma capacidade biológica e a linguagem normatizada. Tal aspecto indica que há, no ser humano, uma proclividade à criação de referenciais ou uma tendência a orientarse por e a partir deles.

Em paralelo, o anseio de esquadrinhar padrões a serem seguidos é antigo. Podese mencionar, como marco de empreendimento intelectual, Ética a Nicômaco, de Aristóteles, uma das primeiras obras nesse sentido. Ao resgatar a separação o mundo das ações do mundo das ideias (e projetos), o filósofo explica que "se, pois, para as coisas que fazemos existe um fim que desejamos por ele mesmo e tudo o mais é desejado no interesse desse fim; [...] evidentemente tal fim será o bem, ou antes, o sumo bem" (ARISTÓTELES, 1991: 6). A felicidade residiria não na honra, qualidade atribuída por outros, mas na virtude, padrão etéreo e mais bem estruturado conforme a determinação cultural de cada época.

Peter Berger e Thomas Luckmann (2013), ao abordarem o processo de construção social da realidade, enfatizam a necessidade do indivíduo de orientação por referências próximas, sendo os sistemas que lhe servem de base em si dotados de capacidade para formular hierarquias de prioridades. Além da fala, a própria consciência, como delimitação de percepção e de um campo para se agir, incluise aí. "A consciência é sempre intencional. Sempre 'tende para' ou é dirigida para objetos. Nunca podemos apreender um suposto substrato da consciência enquanto tal, mas somente a consciência de tal ou qual coisa" (Ibid., 2013: 37). A consciência teria, portanto, em sua essência, um viés de determinação por si própria, independente da existência de coação de agentes externos como estruturas de poder ou de persuasão ideológica.

O uso de uma tendência de pensamento é a solução natural para a sobrevivência cotidiana. Um exemplo dessa tendência, de acordo com Berger e Luckmann (2013), está no reconhecimento do interlocutor nas conversas face a face, que, embora exista a dificuldade de se estabelecer um padrão rígido, é padronizado dentro das generalizações da vida cotidiana. Já quando o indivíduo depara com o desconhecido, cada nova situação é trazida para a proximidade de tipos preestabelecidos e que Ihe são familiares. Segundo os autores, "A realidade da vida cotidiana contém esquemas tipificadores em termos dos quais os outros são apreendidos, sendo estabelecidos os modos como 'lidamos' com eles nos encontros face a face" (Ibid., 2013: 48).

${ }^{1}$ Berger, Luckmann e Ahmed têm como raiz comum as premissas tomadas do filósofo Max Scheler, evidenciando uma predisposição à explicação social e de comportamentos por meio da fenomenologia. As semelhanças não param por aí, mas há também muitos pontos de diferença. A matriz comum evidencia que a perspectiva inicial é a mesma. As diferenças não são excludentes, mas complementares.

${ }^{2}$ No original: "'the drama of contingency' how we are touched by what comes near".
A tendência para a aproximação com o familiar também é abordada por Sara $\operatorname{Ahmed}^{1}$ (2010) por meio do que chamou de "drama da contingência", ou seja, "como somos tocados pelo que está próximo"2 (Ibid.: 574, tradução nossa). A autora, que aborda a normatização da felicidade, traz à luz em seu estudo a origem do termo happiness, que apresenta raiz etimológica em hap, acontecimento, causalidade. Mas, que, com o passar do tempo, o que era acontecimento casual, boa sorte ou fortuna, teria deixado de ser produto do acaso para se tornar algo com um significado e possível de ser perseguido. Essa crítica de Ahmed (2010) à normatização é complementar ao argumento de Berger e Luckmann (2013) de que há outros fatores coercitivos que normatizam a experiência humana, e que a inclinação natural, tanto da fala quanto do foco da consciência para o mundo que nos é dado, não indica que determinado comportamento seja fruto de escolhas individuais autônomas. Um desses fatores, e talvez o primeiro deles, de acordo com os autores, seria o tempo: "A mesma estrutura temporal, como já indicado, é coercitiva. Não posso inverter à vontade as sequências impostas por ela, 'primeiro as primeiras coisas' é um elemento essencial no meu conhecimento da vida cotidiana" (Ibid.: 45). 
A partir daí, trazendo o problema para o contexto atual, em tempos de narrativas que se formam e transformam permanentemente nas redes sociais, poderíamos considerar como fator coercitivo e normativo o algoritmo que dispõe as informações na página pessoal de cada usuário. Como se sabe, tal ordenamento não se dá de forma aleatória, muito antes pelo contrário, segue uma lógica própria, que não é evidente ao usuário comum, mas que se orienta a partir da vontade mercadológica do grupo empresarial que controla a plataforma.

Ao se deter sobre a forma como o conceito de hapinness é construído de forma disciplinar, uma emoção que é normatizada diz que o conceito passa também a exercer uma vontade: "a felicidade traduz seu desejo em uma política, uma política desejosa, uma política que demanda que outros vivam conforme um anseio" (AHMED, 2010: 572, tradução nossa). Então o projeto, anteriormente um desejo individual, é proposto ao coletivo e, em nome de um bem comum, passam a ser proclamadas normas que devem ser aceitas como receitas - para a felicidade, no caso do objeto de estudo de Ahmed (2010), ou para um futuro melhor, no caso da política de um país.

A partir dessas noções, é possível analisar situações quando um normativo - que é quase um imperativo - prepondera em conversações de redes sociais. Foi o que aconteceu momentos antes da votação na Câmara dos Deputados que decidiria pelo encaminhamento ou não do processo de impeachment da presidenta Dilma Rousseff para o Senado Federal. O deputado Francisco Everardo Oliveira Silva, o Tiririca, do Partido da República (PR) e eleito pelo estado de São Paulo, ao anunciar que seu posicionamento seria mantido em sigilo até o momento da votação, acabou gerando expectativa e discussões acaloradas. Neste artigo, foram analisados os comentários no perfil da edição brasileira do jornal El País no Facebook (Figura 1), que repercutiram também em perfis de outros periódicos.
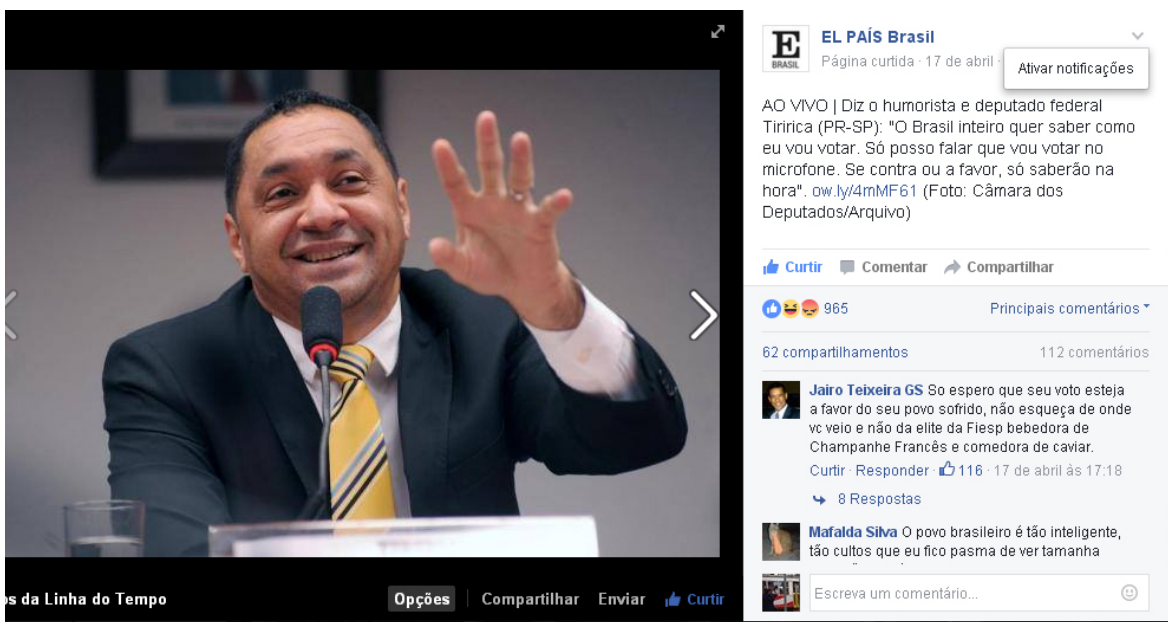

Figura 1: Post do El País sobre o voto de Tirica (AO VIVO..., 2016).

"O Brasil inteiro quer saber como eu vou votar. Só posso falar que vou votar no microfone. Se contra ou a favor, só saberão na hora", diz o texto introdutório do post, com a declaração de Tiririca. Na ausência de um projeto, que seria a posição do deputado Tiririca, e que criaria o suspense em torno de sua participação, podese verificar uma provocação pelo espetáculo, ou seja, pela incitação à manifestação dos usuários em torno de suas posições e daquilo que eles entenderiam como o correto, como a norma. Tomamos como exemplos, inicialmente, os dois comentários que geraram mais respostas na discussão sobre o voto do deputado (AO VIVO..., 2016). As duas manifestações, definitivas em seus posicionamentos, podem ser encaradas como aqueles marcos definidores para os dois grupos que entrariam em choque no decorrer da discussão. Um entendimento que encontra guarida no argumento de Bruno Latour (2012: 55) de que "não existe grupo sem oficial de recrutamento. Não há rebanho de ovelhas sem seu pastor". 
So espero que seu voto esteja a favor do seu povo sofrido, não esqueça de onde vc veio e não da elite da Fiesp bebedora de Champanhe Francês e comedora de caviar. (J.G.S.)

Acho que ele irá votar a favor do impeachment, ele não é doido de enterrar a sua vida politica por uma presidente que não está nem aí para este deputado. Isso também poderá respingar em sua carreira de humorista na TV, fiquem vendo. (S.L.N.)

\section{Grupo, alinhamento e preconceito}

À parte o conceito de felicidade no século XXI ser resultado de uma construção histórico-ideológica e, que assim sendo, cada vez mais perde força como norma em função das características das sociedades pós-modernas, trata-se de um conceito combatido por não ter conseguido abarcar por completo a diversidade das preferências dos seres humanos. Por outro lado, parece prudente imaginarmos que qualquer tentativa de generalização, de representação de um grupo a partir de suas vontades, implicaria necessariamente na produção de uma parcela de indivíduos não contemplados, mas que, ainda assim, por outros motivos, permaneceriam unidos a esse grupo por outras vontades ou características menos representativas. De acordo com Charaudeau e Maingueneau (2014: 248), a noção de generalização, colocada em oposição à de discriminação nos campos da filosofia e da psicologia, é utilizada na linguística para indicar a substituição "por uma regra única ou por regras parcialmente idênticas, de um conjunto de regras que se aplicam a fatos distintos".

É indiscutível que categorizações ou generalizações cumprem um papel importante na compreensão dos fenômenos, ainda que não sejam específicas ou irrefutáveis, justamente porque pretendem alcançar não as individualidades, mas o conjunto ou o grupo. As ausências, os silêncios presentes nas generalizações, que não significam necessariamente a desconsideração daquilo que não está representado na ideia geral, não impedem que elas sejam ferramentas indispensáveis para o tratamento de questões que envolvem conjuntos ou grupos. As justificativas para o uso da generalização ou da categorização como forma de encerrar uma matéria em determinado grupo possível de ser definido, estas sim, sejam temporais, econômicas, políticas ou ideológicas, podem mascarar intencionalidades, preferências e preconceitos de toda ordem. $\mathrm{O}$ uso, ao longo do tempo, de repetidas ideias gerais para significar qualquer conjunto implica necessariamente em ausências e silêncios. E quando pensamos que a normatização, em parte decorre de projetos repetidamente enunciados, percebemos que na generalização há uma força que constrange o indivíduo a agir dentro daquilo que é considerado normalidade.

Há que diferenciar-se, entretanto, norma, no sentido prescritivo - ou seja, norma como uma imposição, uma regra, seja ela gramatical, jurídica ou cultural, que determina a coisa a ser feita -, e norma como o que é tomado por normalidade, ou algo que, diante da recorrência (normativa), apesar de também apresentar um poder de constrangimento, é o esperado, ainda que não seja o determinado. A existência de alguma forma de normatização, seja em torno dos objetivos, seja em relação aos pressupostos da sociedade em que se vive, é um elemento presente em todos os povos civilizados. E assim, os indivíduos, quando fogem a essas regras, tendem, no mínimo, a causar certo estranhamento. Dependendo da regra e da sociedade, porém, esse estranhamento pode ganhar outro tipo de contorno, gerando oposição pública, rupturas e até mesmo desencadeando conflitos mais sérios.

Um bom exemplo desse tipo de conflito é o dos grupos de vegetarianos que, além de optarem por não consumir proteína animal, se opõem veementemente àqueles que consomem. Em seus discursos, não raro os integrantes desses grupos costumam rotular os consumidores de proteína animal como assassinos. 
O uso desse tipo de discurso é uma tentativa de normatização. Nessa tentativa, consumidores de proteína animal são categorizados pejorativamente, tendo suas imagens associadas a algo já enraizado no imaginário social, que é a imagem do assassínio - portanto, algo perigoso, covarde, criminoso, cruel, merecedor de desprezo e do alijamento do convívio em sociedade, e assim por diante.

Essa tentativa de normatização frequentemente se repete no campo político, quando um grupo ou corrente pretende sobrepor sua perspectiva em relação ao outro. Ao utilizar-se de determinados elementos em seu discurso, essas tentativas de normatização promovem o distanciamento ou aprofundam ainda mais as rupturas já existentes. Em algo parecido com o que Joseph Goebbels já havia sistematizado em suas estratégias de propaganda, em relação ao que chamara simplificação da imagem do inimigo, alguns autores como Peter Gay (1995), tratam esse tipo de discurso como a estratégia da criação de outro conveniente, ou de um inimigo comum.

O biólogo francês, Felix le Dantec, insistiu que toda unidade social, da família para a nação, poderia existir apenas pela virtude de ter algum "inimigo comum". A unidade familiar luta contra muitas forças que ameaçam a cada pessoa que pertença a essa unidade. 0 clube exclusivo, Legião Americana, a nação propriamente dita, existe para derrotar os inimigos comuns de seus membros. A favor da visão de Le Dantec está a bem conhecida manobra maquiavélica de criar um inimigo comum para cimentar um sentimento de pertencimento de grupo. Hitler criou a ameaça Judaica mais para cimentar o domínio Nazista sobre a Alemanha do que para destruir os Judeus ${ }^{3}$. (ALLPORT, 1979: 41, tradução nossa).

${ }^{3}$ No original: "The French biologist, Felix le Dantec, insisted that every social unit from the Family to the nation could exist only by virtue of having some 'common enemy'. The family unit fights many threatening forces that menace each person who belongs to the unit. The exclusive club, the American Legion, the nation itself, exists to defeat the common enemies of its members. In favor of Le Dantec's view is the wellknown Machiavellian trick of creating a common enemy in order to cement an in-group".

${ }^{4}$ No original: "Neither of these famous men of intellect allows for individual diferences among women, nor asks whether their alleged atributes are in fact more common in the female than in the male sex".

${ }^{5}$ No original: "Each individual tends to see in his in-group the precise pattern of security that he himself requires. [...] To a considerable degree all minority groups suffer from the sema state of marginality, with its haunting consequences of insecurity, conflict, and irritation. Every minority group finds itself in a larger society where many custos, many values, many practices are prescribed".

${ }^{6}$ No original: "all groups (whether in-groups or reference groups) develop a way of living with characteristic codes and beliefs, standards and 'enemies' to suit their own adaptative needs".
Segundo Gordon Allport (1979), há dois ingredientes básicos e fundamentais que estão associados a esse tema: a difamação e a generalização grosseira. Utilizando o exemplo de autores como Schopenhauer e Chesterfield, alegadamente antifeministas, Allport (1979: 35, tradução nossa) lembra que "nenhum desses famosos homens de intelecto permitem diferenças individuais entre mulheres, nem se questionam se seus alegados atributos são de fato mais comuns no sexo feminino do que no sexo masculino"4.

Para o autor, o exercício do preconceito também implica na confirmação do status do indivíduo preconceituoso, no reforço de sua segurança e do contentamento com seu próprio grupo de pertencimento. Por sua vez, a inserção dos indivíduos em algum grupo de pertencimento pode ser facilitada, segundo o autor, por fatores como as recompensas que o indivíduo recebe e que funcionam como incentivo, ou até mesmo a felicidade que esses grupos proporcionam - embora tais fatores não possam ser responsabilizados sozinhos pelo nascimento da vontade no indivíduo que o inclina a fazer parte de um grupo social. A questão do pertencimento também parece passar pela ideia de o indivíduo garantir, através da ruptura que promove com os outros grupos, a segurança de si próprio:

Cada indivíduo tende a ver em seu grupo o padrão preciso de segurança que ele mesmo requer. [...] Em um grau considerável, todos os grupos minoritários sofrem do mesmo estado de marginalidade, com suas assombrosas consequências de insegurança, conflito e irritação. Todo grupo minoritário se encontra numa ampla sociedade onde muitos padrões, muitos valores, muitas práticas são prescritas ${ }^{5}$. (Ibid.: 36-38, tradução nossa).

Assim, os grupos minoritários sofrem certa pressão por parte dos grupos dominantes para que façam destes seus grupos de referência. Segundo Allport (1979: 39, tradução nossa), a principal teoria do preconceito sustenta que "todos os grupos desenvolvem uma maneira de viver com códigos e crenças característicos, padrões e 'inimigos' que servem suas próprias necessidades adaptativas" ${ }^{6}$. Além disso, as pressões internas nos grupos fazem com que sejam aceitas posições em 
${ }^{7}$ No original: "School spirit is never so strong as when the time for an athletic contest with the traditional 'enemy' approaches".

${ }^{8}$ No original: "Now there is no denying that the presence of a threatening common enemy will coemente the ingroup sense of any organized aggregate of people". relação a preferências e, da mesma forma, fazendo com que os inimigos, de um grupo sejam considerados inimigos por todos os membros de um grupo.

De acordo o autor, embora um grupo de pertencimento sempre implique na existência de um grupo de não pertencimento correspondente, essa declaração tem pouca importância. $O$ que realmente importa é saber se a lealdade de alguém para com um grupo de pertencimento significa automaticamente deslealdade ou hostilidade em relação a outros grupos de fora. É uma boa pergunta...

Talvez não seja o caso de significar automaticamente uma deslealdade ou hostilidade, ou seja, não significar necessariamente que a primeira reação em relação ao grupo externo seja negativa. Mas é tentador supor que conforme as questões forem se tornando mais complexas, ou conforme for surgindo a necessidade de se realizar escolhas de caráter excludente, a tendência seja que o indivíduo se comporte de maneira leal com seu grupo e, se for o caso, se isso for necessário para sua segurança ou a de seu grupo, com hostilidade em relação aos grupos de fora.

Essa poderia ser a explicação de por que em momentos de crise política normalmente os parlamentos se encontram com ânimos tão exaltados que, não raro, refletem em confrontos físicos. Quando o autor diz que o "espírito escolar nunca é tão forte como quando no período de uma competição atlética o tradicional 'inimigo' se aproxima"7 (Ibid.: 41, tradução nossa), ele também dá base para a sustentação do argumento que a tradição de disputa entre dois partidos políticos aumenta entre eles sua rivalidade: "Agora não há como negar que a presença de um inimigo comum e ameaçador irá cimentar o senso de pertencimento a um grupo de qualquer agregado de pessoas ${ }^{81}$ (Ibid.: 42, tradução nossa).

O autor lembra que a adversidade é capaz de fazer uma família crescer com um sentido de coesão único, assim como uma nação jamais está tão unida como em tempo de guerra, mas a ênfase para esse tipo de constatação, segundo Allport (1979), deve ser colocada no desejo por segurança e não na hostilidade propriamente dita. Para o autor, a hostilidade, apesar de reforçar o senso de pertencimento a determinado grupo, não é condição para esse pertencimento, e que o partidarismo e o etnocentrismo se desenvolvem como resultado da importância para a própria sobrevivência e autoestima do indivíduo e do grupo.

A votação para o encaminhamento ao Senado do processo de impeachment da presidenta Dilma Rousseff refletiu muito claramente as questões de lealdade ao grupo e confronto. Algumas bancadas, como a do Partido Democrático Trabalhista (PDT), fecharam o voto pelo não encaminhamento do processo ao Senado, o que fez que alguns congressistas, mesmo contrários à decisão do grupo, fossem leais ao partido e votassem contra a própria vontade. Em outro momento, a provocação por parte de um parlamentar de direita que exaltava integrantes do regime militar foi respondida com uma cusparada por um deputado da esquerda apoiador do governo. Por certo, a questão ideológica está profundamente envolvida com a origem dos conflitos político-partidários.

De acordo com o autor italiano Giovanni Sartori (1969), as ideologias envolvem uma série de pensamentos que surgem a partir de determinados sistemas de crenças que, por sua vez, são formados por elementos, conceitos, valores, que são acreditados ou levados em consideração. Para o autor, quando duas ideologias diferentes colidem - e o motivo é a divergência em torno de elementos profundamente enraizados em seus sistemas de crença - a tendência é que a única reação possível seja mesmo o confronto direto. Alguns desses aspectos são perfeitamente aplicáveis ao caso que analisamos. Vejamos as reações ao comentário do usuário J.G.S., exposto anteriormente: 
Isso vote contra o Golpe! (E.V.)

"o impeachment tem dois objetivos: roubar o poder do PT; enganar as pessoas para que pensem que a corrupção foi resolvida e proteger os verdadeiros corruptos": glenn greenwald. (F.R.C.)

\section{O Impeachment da Lava-jato}

Para o PT, a Lava-jato são favas contadas: vão todos pra cadeia. Com ou sem impeachment!

Para os outros, qua ainda estão na "surdina", é preciso acabar com ela, o quanto antes.

Como Dilma não se permite fazer isto, impeachment nela! Pra substitui-la por alguem mais, digamos, compreensivo.

Logo, este é o impeachment da Lava-jato.

Simples assim. Quem viver verá! (H.M.)

Há, sem dúvida, elementos de concordância com o primeiro comentário de J.G.S. e, ao mesmo tempo, de complementariedade, na busca de acrescentar argumentos no objetivo persuasivo de arregimentar o voto do deputado supostamente "indeciso". Também não há dúvida de que se forma um grupo de oposição aos que apoiam S.L.N. em seu comentário. Vejamos os próximos exemplos:

Não dá para entender a pessoa gostar de ser pobre!

Eu já fui e hoje tenho uma melhor vida por força de meu trabalho. \#republicadamortadela. (S.R.).

A Era da Mandioca e do Vento Ensacado, deverá encerrar hoje na Câmara dos Deputados um ciclo de completa ingovernabilidade, incompetência, complacência e omissão com o mar de corrupção que assolou o país.

O efeito prático desse DESgoverno é o desastre econômico que estamos vivendo, tendo um PIB negativo pelo terceiro ano, gerando o desastre social do desemprego, fechamento de fábricas, inflação e juros estratosféricos.

A trajetória de Dilma, Lula e do PT, poderão brevemente serem vistas no Museu Nacional do Lixo da História. (C.D.B.)

Espero que não decepcione o estado de São Paulo em senhor Tiririca vote sim é seja um herói da Nação brasileira!! (D.B.B.)

Podemos notar que durante a tentativa de normatizar o posicionamento do deputado Tiririca há uma linha de respeito mútuo estabelecida entre os dois grupos, que não permite a agressividade, embora se perceba claramente a adversidade entre as duas correntes de opinião. A beligerância linguística - e também comentários abonatórios ao deputado - só se apresenta após Tiririca revelar seu posicionamento, favorável ao prosseguimento do processo. Enquanto há disputa, os grupos mantêm certo prurido em não avançar determinados limites de expressão, mas a partir do voto de Tiririca, que marca o início de uma escalada de animosidades entre os participantes da discussão, a agressividade e o ódio passam a ser liberados em grandes doses.

Podemos dizer que essa expressividade do ódio, no caso do voto do deputado brasileiro, foi resultado do choque entre duas correntes político-ideológicas: os apoiadores e os opositores do governo Dilma Rousseff. Duas correntes que podem ser representadas - mas que não são formadas apenas por aquilo que Ihes representa - por ideologias distintas, mas que, aparte, se originarem de um posicionamento político contraditório (e aqui está nosso objeto), se propõem normativas e atuam normativamente. Uma atividade normativa que parece não se interessar pelo consenso. Pelo contrário, que atua de maneira irredutível em direção ao ódio e ao conflito irredutível. 


\section{Ódio e discurso}

A ciência que domina o estudo do ódio é a psicanálise. Ela própria surge a partir do século XIX buscando entender, entre outras coisas, as origens e reações violentas dos homens, seus afetos e seus ódios. Esse século que presenciou importantes movimentos migratórios também foi o palco de uma série de estudos que procuravam justificar cientificamente, sobretudo na Europa, o desprezo pelo estrangeiro (GAY, 1995). Enquanto de um lado fortalecia-se o ódio racial, de outro nascia a busca pela explicação de tais emoções. No campo político, a linguagem belicosa ganhava uma figura destaque: Otto Von Bismarck.

Sem dúvida, imagens belicosas podem ocorrer com facilidade a qualquer um que fale de política. Certamente, rivais políticos ferozes como Gladstone e Disraeli não poupavam um ao outro, pelo menos em particular. Mas em público preservavam um decoro que Bismark se recusava a ter. Sua oratória tinha uma combatividade especial, e seus planos muitas vezes acompanhavam as palavras. (Ibid.: 258).

Bismark não inaugura o ódio político, mas sua linguagem pitoresca, carregada de metáforas sobre caça e duelos mortais, marca o universo dos discursos políticos justamente por abandonar um elemento que até então era valorizado na política e em seus atores: o decoro. Essa qualidade, relacionada à "seriedade e decência ao agir; dignidade", e ainda "compostura nas maneiras" (DECORO, 2015) necessária para garantir minimamente os interesses e a paz entre os Estados - e que na época era normalmente reservada aos indivíduos mais bem-educados -, passa a perder lugar para a crueza e a brutalidade do homem comum. Com ele ascende a intolerância. A retórica belicosa de Bismarck, prática em sua violência, é o precedente para o que se viu, 50 anos depois, no ódio aos judeus presente no discurso de Adolf Hitler.

Sara Ahmed (2004) parte do questionamento de como emoções como o ódio funcionam para reforçar as coletividades através da forma como elas moldam os outros, e como o ódio funciona organizando alguns elementos contra os outros. A autora critica o argumento de que o ódio é uma defesa contra alguma forma de agressão, sustentando que o surgimento da necessidade de defesa se dá por meio da construção narrativa sobre a coletividade e sobre os outros, e que tais

${ }^{9}$ No original: "Hate is an intense emotion; it involves a feeling of 'againstness' that is always, in the phenomenological sense, intentional. Hate is always hatred of something or somebody, although that something or somebody does not necessarily preexist the emotion". narrativas, às vezes, envolvem uma reconstrução histórica. A definição de Ahmed para o ódio é a de que

Ódio é uma emoção intensa; ela envolve um sentimento de "ser contra" que é sempre, no sentido fenomenológico, intencional. Ódio é sempre aversão a algo ou alguém, embora este algo ou alguém não necessariamente preceda a emoção9. (AHMED, 2004: 49, tradução nossa).

Então, quando alguns dos comentários em relação ao posicionamento do deputado Tiririca de não abrir o voto são carregados de elementos que deixam exacerbar o ódio, podemos dizer que esse ódio tem por objetivo, em primeiro lugar, à identificação dos grupos contrários a partir de representações desfavoráveis, ou à criação do outro conveniente. Vejamos alguns exemplos:

Palhaço vendido, traidor e golpista! (M.M.)

Favorecido pela natureza dos comentários em rede, que tendem a ser curtos, intensos e imediatos, o ódio também parece refletir muito bem a inclinação para a simplificação, ou seja, para a associação direta de um posicionamento a outro que não necessariamente acompanha o primeiro. No caso do comentário que se refere ao deputado, ao supor que o voto seria favorável ao impeachment, como "palhaço vendido, traidor e golpista", há em primeiro lugar uma tentativa de deslegitimar uma opinião que pode ter sido baseada em um argumento técnico. 
Analisando individualmente cada adjetivo direcionado ao deputado, vemos que refletem ideias negativas que encontram ressonância em outros discursos sobre as votações da câmara: é o caso de "palhaço vendido", supondo um voto comprado; "traidor", que supõe que Tiririca devia lealdade ao governo independentemente de sua compreensão pessoal para com os fatos; e, por fim, "golpista", que vincula todos os votos favoráveis ao impeachment a uma tentativa de golpe de Estado.

O próximo exemplo traz um comentário favorável ao impeachment, mas que se torna peculiar porque, ao dizer "o cara não é tão burro", E.C. está exercendo uma tentativa de normatização através da ofensividade e do ódio, que são direcionados tanto ao deputado quanto a Dilma Rousseff.

O cara não é tão burro, óbvio que vai votar contra a anta.

Ou seja, nos dois casos, nos parece bastante claro que há por trás dos comentários, para além da expressão de discursos que podem ser enquadrados como discursos do ódio, uma natureza normatizadora, um desejo de estabelecer um marco normativo - algo que se aproxima no Direito do instituto da coerção - ou seja, a obediência forçosa a determinada norma. Os emissores desses discursos esperam que seus argumentos sejam tomados por válidos e que suas palavras sejam seguidas como a lei.

Esse tipo de disputa em nível de discurso, na tentativa de que um prevaleça em relação ao outro, num meio como o virtual (que prescinde da presença física), aliado a uma causa polêmica como o voto contra ou a favor do impeachment, faz com que os critérios para o estabelecimento de uma discussão civilizada sejam completamente ofuscados pela oportunidade de manifestação das vontades individuais, da intolerância e do ódio. O volume de ofensividade e ódio, assim como o de simplificações e manifestações preconceituosas, acaba se sobressaindo em relação aos argumentos que poderiam construir um entendimento conjunto, politizado, consensual, equilibrado.

Quando se atinge este estado de exasperação e de disseminação de ódios, a guerra civil adquire formas catastróficas, para ela contribuindo todos, mesmo sem de tal haverem consciência. Essa psicose coletiva é, aliás, característica dos períodos confusos ou revolucionários. Todos desconfiam de todos e todos procuram satisfazer, inicialmente, os seus rancores ou despeitos, mediante denúncias sucessivas e contínuas, absurdas ou iníquas. (VIANA, 1960: 181).

O autor do campo da psicanálise Mário Gonçalves Viana acredita que a escalada do ódio nos discursos nos revela uma realidade preocupante. $O$ primeiro ponto para compreender os discursos contra o posicionamento do deputado Tiririca é perceber que a maioria desses discursos pode partir de algum um grau de projeção, ao menos em relação às diversas tentativas de antecipar o voto do congressista. Também é possível constatar que a presença de mensagens encorajadoras em relação ao posicionamento do deputado, como "Muito bem, Tiririca, sem pressão!", foram mais raras em relação às mensagens irônicas e ofensivas como "FDP", "Abestado", "Palhaço, agora mais que nunca palhaço", "O Safado votou a favor da Dilma" e, ainda, "Tiririca Presidente 2018".

\section{Considerações finais}

Dentro da brevidade possível em um artigo, buscamos apresentar o resultado da observação de um aspecto recorrente na problematização das manifestações políticas nas redes sociais. Nossa observação partiu do pressuposto da existência de uma inclinação socialmente estabilizada no homem em direção à estruturação e à normatização. $\mathrm{O}$ que observarmos foi que, num ambiente virtual como aquele fornecido pelo El País no Facebook para a discussão política, envolvendo um tema potencialmente polêmico e reunindo atores (seguidores da página do jornal 
espanhol no Brasil) de diferentes correntes políticas, nosso pressuposto se reforçou na medida em que o número de manifestações com um teor normativo foi bastante superior ao daqueles discursos que procuravam a construção de um significado em conjunto. Ainda que não tenham sido os objetos de análise e aprofundamento, consideramos em nossa observação a existência de um poder, eventualmente exercido, que partiria de fatores de agenciamento ou de influência ideológica para a formulação ou tentativa de estabelecimento de normas sociais. E para observarmos a dinâmica da formação dos grupos e seus comportamentos em relação a padrões de inclusão/identificação e de exclusão/repulsa, chegando às manifestações do ódio nas mídias sociais, encontramos maior segurança científica por meio da utilização de um embasamento teórico com origem na psicanálise.

Se inicialmente a norma surge como o bem, ou o "sumo bem", na definição precisa de Aristóteles, é interessante notar que, na contemporaneidade enfatizada por suportes tecnológicos dinâmicos e ubíquos, a intenção de pregar seu bem individual como universal ao coletivo acarreta frequentemente em explosões de agressividade por sujeitos que, aparentemente, ainda não estão em ambientes de convulsão social. Tal transcurso - o da imposição da vontade pela violência simbólica ou física - está longe de ser uma manifestação que consista em novidade, uma vez que, durante o século $X X$, por exemplo, essa realidade também pôde ser percebida, sobretudo, por meio do anseio da implantação de utopias ou metanarrativas legitimadoras. A relação entre as motivações e os processos envolvidos nos diálogos intransigentes nas redes sociais, por sua vez, também se tornaram mais complexas ao absorver novas demandas e argumentos. Nesse ponto, parece interessante que se explore de que maneira os agentes desses conflitos se apropriam dessas novas demandas, como absorvem os novos argumentos e os fundem às mesmas metanarrativas legitimadoras, revolucionando seu poder e perpetuando o conflito ideológico.

Basicamente, quando dizemos que os grupos ou sistemas têm uma organização ou uma estrutura, referimo-nos a padrões normativos standarizados, direitos, regras de comportamento etc. Consequentemente, no cerne da análise sociológica reside uma preocupação com as normas, com os padrões esperados de comportamento mantidos nas mentes dos indivíduos. Assim, o sociólogo está interessado em tudo aquilo que apoia ou mina as normas, incluindo a divergência, a inovação ou a rebelião. (LIPSET, 1992: 26).

Por outro lado, foi possível perceber também que sobressai nos diálogos das redes sociais uma busca por satisfação, no sentido de saciedade, da vontade do discurso e do uso do lugar de fala. Essa nova realidade se constitui no imaginário do usuário das redes como se fosse um novo "direito adquirido", que estaria associado ao imaginário da liberdade, e, assim, parece ser tomado como um valor maior no exercício dos debates virtuais. Nesses atos, portanto, o mais importante passa a ser o exercício desse direito. Passa a ser deixar uma impressão ou uma opinião válida, uma última palavra que se perpetue, mesmo que isso implique em um discurso ofensivo como as diversas formas de discurso do ódio que encontramos na discussão sobre o voto do deputado Tiririca. Sabemos que, em parte, esse fenômeno encontra a facilidade das redes que permitem aos indivíduos valerem-se de uma relativa segurança que a ausência física oferece, pois, teoricamente, não há reação ou risco físico imediatos envolvidos durante o processo comunicativo. Mas, por outro lado, vale lembrar que a palavra publicada tem uma sobrevivência no tempo que é superior à palavra falada, e isso possibilita que esses mesmos debates se estendam por mais tempo e que essas palavras e opiniões sejam submetidas ao escrutínio, por vezes superficial e tendencioso, de uma análise tomada de emoção. E mesmo assim, os indivíduos parecem preferir ser autores de palavras carregadas de poder destrutivo ou irônico do que estabelecer alguma forma de vínculo construtivo, quando sentem seus sistemas de crença ameaçados por outro discurso. 
Um trabalho mais amplo poderia identificar mais nuances desse processo, em que formas de discursos embasam-se: pela ironia, pela ofensa, analogias a animais, palavras de baixo calão e escatológicas, entre outras categorizações possíveis. Há que se apreender o sentido, às vezes oculto, presente nos discursos banais do cotidiano em redes associativas, tomadas que estão pela abundância tautológica de expressões individuais ou coletivas. Se no século IV a.C. na Grécia a felicidade era medida pelo virtuosismo na conduta, na era do virtual, a busca pela virtude é a tônica nas expressões individuais nas redes sociais. Virtus enquanto potência que se realiza, nos casos aqui expostos, pelo ódio.

\section{Referências}

AHMED, S. Killing joy: feminism and the history of happiness. Signs - Journal of Women in Culture and Society, Boston, v. 35, n. 3, p. 571-594, 2010.

. The cultural politics of emotion. New York: Routledge, 2004.

ALLPORT, G. W. The nature of prejudice. New York: Basic Books, 1979.

AO VIVO: diz o humorista e deputado... El País Brasil, [s.I.], 17 abr. 2016. Facebook. Disponível em: <http://bit.ly/2k4thft>. Acesso em: 18 jan. 2017.

ARISTÓTELES. Ética a Nicômaco. São Paulo: Nova Fronteira, 1991.

BERGER, P.; LUCKMANN, T. A construção social da realidade: tratado de sociologia do conhecimento. Petrópolis: Vozes, 2013.

ChARAUdeAU, P.; MAINGUENEAU, D. Dicionário de análise do discurso. São Paulo: Contexto, 2014.

DECORO. In: DICIONÁRIO on-line. São Paulo: Melhoramentos, 2015. Disponível em: <http://bit.ly/2jUMTPi>. Acesso em: 30 jan. 2017.

GAY, P. O cultivo do ódio. São Paulo: Companhia das Letras, 1995.

KLEIN, M.; RIVIERE, J. Amor, ódio e reparação: as emoções básicas do homem do ponto de vista psicanalítico. 2. ed. Rio de Janeiro: Imago, 1975.

LATOUR, B. Reagregando o social: uma introdução à Teoria do Ator-Rede. Salvador: Edufba, 2012; Bauru: Edusc, 2012.

LIPSET, S. M. Consenso e conflito. Lisboa: Gradiva, 1992.

SARTORI, G. Politics, ideology and belief systems. American Political Science Review, London, v. 63, n. 2, p. 398-411, 1969.

VIANA, M. G. Psicologia do ódio. Porto: Porto, 1960. 